\title{
DrogadicÇão: \\ TENTATIVA DE SUICÍDIO E/OU ELABORAÇÃO? ${ }^{1}$
}

\author{
Natallie Karim Rodrigues Mansilla \\ Victor Eduardo Silva Bento ${ }^{\star \star}$
}

\begin{abstract}
RESUMO
Interrogou-se se a drogadicção compreender-se-ia como gozo pela descarga da pulsão de morte sobre si próprio, ou se neste ato haveria simultaneamente a convocação da pulsão de vida. Concluiu-se existir a ação simultânea das pulsões de morte e de vida. A drogadicção traria um silêncio e alguma perspectiva de "simbolização". Esta foi encontrada entre a brincadeira infantil e o ideal de cura analítica pelo acesso ao simbólico através do luto pela perda primordial. A auto-destruição, a tentativa de suicídio pela drogadicção, foram entendidas como melancolia e negação maníaca.
\end{abstract}

Palavras-chave: Drogadicção. Toxicomania. Suicídio. Elaboração. Psicanálise

\section{DRUG ADDICTION: SUICIDE ATTEMPT AND/OR ELABORATION?}

\begin{abstract}
It was questioned if drug addiction could be understood as enjoyment through the discharge of death instinct on oneself, or if it would be simultaneously the action of life instinct. It was concluded that it would be both death and life instincts acting at the same time. Drug addiction brings concomitantly silence and some "symbolization". It was found the elaboration between children's joke and the ideal of the analytical cure in the symbolic access, mourning for the original loss. Self-destruction and the suicide attempt by ingesting drugs were understood as melancholy and maniac denial at the same time.
\end{abstract}

Keywords: Drug Addiction. Toxicomania. Suicide. Elaboration. Psychoanalysis.

\section{INTRODUÇão}

^ Bolsista de Extensão do CET - Centro de Estudos das Toxicomanias Dr. Claude Olievenstein da UFPR - 2001 e 2002; Psicóloga Clínica do Hospital do II Centro Integrado de Defesa Aérea e Controle de Tráfego Aéreo - Comando da Aeronáutica - Curitiba / Paraná.

$\star \star$ Doutor em Psicopatologia Fundamental e Psicanálise pela Universidade Paris 7; Professor do Departamento de Psicologia da UFPR (02/1984 - 05/2005); Diretor do CET - Centro de Estudos das Toxicomanias Dr. Claude Olievenstein da UFPR (10/1999 - 05/2005); Professor do Departamento de Psicometria do Instituto de Psicologia da UFRJ (desde 09/2005). Endereço: Rua Domingos Ferreira 180 / Cob. 02 - Copacabana / Rio de Janeiro / CEP: 22050-010.

E-mail: victorbento@oi.com.br 
É inegável a relação de auto-destruição que o drogadicto (ou toxicômano) estabelece com seu corpo a partir do ato de se auto-administrar a droga. Nos casos de overdose esta auto-destruição chega mesmo a assumir a aparência de uma tentativa de suicídio, ou culmina no próprio suicídio quando é seguida pelo óbito do paciente. Se apesar da consciência de estar se auto-destruindo ele insiste em se drogar, pode-se questionar: O prazer do drogadicto em se drogar se reduz a uma espécie de gozo pela descarga pura e simples da pulsão de morte sobre si mesmo? Ou, além da auto-destruição, da busca da descarga da pulsão de morte auto-dirigida, haveria simultaneamente algum outro motivo, alguma convocação da pulsão de vida, na base deste impulso toxicofílico, nestes atos de se auto-administrar a droga? Havendo a inserção da pulsão de vida na drogadicção, poder-se-ia pensar tais atos de se drogar como trazendo alguma perspectiva de elaboração? A hipótese que guia a presente pesquisa é a de que a autodestruição observada nos drogadictos pode vir acompanhada de alguma perspectiva elaborativa. No desenvolvimento deste estudo pretende-se discutir que o sujeito drogadicto é aquele para quem o luto primordial se deu de forma insatisfatória, parcial. Simbolicamente, estará se falando de um sujeito que, através do vínculo fusional com a droga, repete a fusão original com a mãe. Por isso seu aniquilamento significará também o aniquilamento desta mãe que imaginariamente o completa. A autodestruição poderia, então, significar um ataque a si próprio para atacar a mãe e, assim, romper este vínculo, fazendo algum luto, embora um luto parcial, insatisfatório. Desta forma, pode-se hipotetizar que a drogadicção comporta simultaneamente a repetição da fusão primordial com o objeto materno e a elaboração parcial da perda deste vínculo, desta completude ilusória.

\section{Sobre o TOXICÔMANo MELANCÓlico E SUA AGRESSÃo \\ A SI MESMO PARA ATACAR O OBJETO MATERNO PRIMORDIAL E FAZER SEU "LUTO PARCIAL"}

O trabalho de luto consiste na elaboração de uma perda através da decatexia objetal. A libido retirada do objeto retorna para ego. Este, identificando-se secundariamente com o objeto, elabora assim sua perda. No impedimento do luto, o sujeito se vê remetido a uma perda da possibilidade de simbolização do ego, fazendo, então, uma melancolia. A esse respeito, vale lembrar Kovács (1992) quando a autora afirma que os sintomas melancólicos são manifestações psicóticas decorrentes da dificuldade de simbolização.

O toxicômano parece situar-se como um sujeito que realiza parcialmente o luto da dependência primordial do objeto materno. Pois se desliga da fusão em relação à mãe, mas substitui sua dependência desta pela dependência das drogas. Passa, assim, a atacar seu próprio corpo para, ao mesmo tempo, atacar simbolicamente o corpo materno, visando uma espécie de ruptura, de "luto" desta fusão original. Um "luto" entre aspas, pois a dependência persiste, o que situará este 
sujeito do lado da melancolia. Kalina et al (1999, p. 82-83) parecem se referir a esta melancolia quando assim escrevem sobre a relação deste sujeito toxicômano com seu corpo:

Pelas características que apresenta, pode-se dizer que, em última análise, $o$ ataque ao próprio corpo é também o ataque do toxicômano à sua mãe. De fato, para a mãe, o corpo de seu filho é parte do próprio self e vice-versa. Deste ângulo interpretativo, a transcendência do limite que o corpo é e simboliza significa ter conseguido a independência da corporeidade materna a que $\mathrm{o}$ adito, em sua fantasia delirante, se encontra fusionado (submetido). Mas, ao mesmo tempo, esta tentativa de dessimbiotização é uma vingança.

Caberia, agora, retornar aos ensinamentos de Freud especificamente sobre a melancolia, a fim de utilizá-los para compreender melhor de que forma esta vingança se processa misturada com a auto-destruição do toxicômano, esse melancólico em essência, conforme se pode supor pela citação acima de Kalina et al. Freud (1917/1974), ao tratar da tendência suicida do melancólico, também afirmará que a chave deste quadro clínico, a explicação das recriminações feitas ao ego, está, na verdade, num ataque que se dirige ao outro. Ocorre, desta forma, uma identificação narcisista, fusional, com um objeto amado e odiado. Não podendo odiá-lo, o melancólico voltaria o ódio contra si mesmo, atacando-se para, assim, atacar o objeto. Freud (1917/1974, p. 284-285) escreverá a esse respeito:

É exclusivamente esse sadismo, que soluciona o enigma da tendência ao suicídio, que torna a melancolia tão interessante - e tão perigosa. Tão imenso é o amor de si mesmo do ego (self-love), que chegamos a reconhecer como sendo o estado primevo do qual provém a vida instintual, e tão vasta é a quantidade de libido narcisista que vemos liberada no medo surgido de uma ameaça à vida, que não podemos conceber como esse ego consente em sua própria destruição. De há muito, é verdade, sabemos que nenhum neurótico abriga pensamentos de suicídio que não consistam em impulsos assassinos contra outros, que ele volta contra si mesmo, mas jamais fomos capazes de explicar que forças interagem para levar a cabo este propósito. A análise da melancolia mostra agora que o ego só pode se matar se, devido ao retorno da catexia objetal, puder tratar a si mesmo como um objeto - se for capaz de dirigir contra si mesmo a hostilidade relacionada a um objeto.

Voltando para o toxicômano, sabe-se que este ataque que ele faz ao corpo poderá levá-lo a uma overdose. Esta surge da necessidade que ele tem de recuperar a certeza de que o corpo atacado não é o seu, mas o da mãe. Kalina et al. (1999, p. 82) escrevem sobre isto: 
$\mathrm{O}$ adito procura, assim, a overdose para recuperar a certeza de que ele não é seu corpo. Quer provar a esse corpo, que agora se apresenta como seu, que está errado, que o limite de tolerância imposto à sua insaciável ansiedade tóxica é facilmente transgredível sem que isso acarrete conseqüências perigosas de qualquer tipo.

No entanto, o corpo não pode acompanhar este ritmo e, mais cedo ou mais tarde, vai se fazer "sentir" pelo adicto. É aí que o toxicômano irá adotar seu projeto suicida. O suicídio aqui terá o caráter de uma solução extrema contra o perigo de uma desintegração psicótica, e também será um ato extremo de vingança contra um corpo que o expulsou: o corpo da mãe.

Parece agora mais claro a forma como se opera o suicídio nas toxicomanias. Porém, como Freud mesmo diz a propósito do melancólico, ainda não está claro como o suicídio efetivo se torna possível diante da aparente força do narcisismo. Mais precisamente, se há um retorno ao ego e valorização do narcisismo na melancolia, por que o melancólico atacaria seu objeto egoico tão valorizado? É a esta indagação que o presente trabalho visa responder. Freud parece conduzir seu leitor a pensar que o ganho narcísico do suicídio liga-se à idéia da melancolia trazer a verdade profunda do Eu. Ele escreverá a esse respeito:

Quando (o melancólico), em sua exacerbada autocrítica, ele se descreve como mesquinho, egoísta, desonesto, carente de independência, alguém cujo único objetivo tem sido ocultar as fraquezas de sua própria natureza, pode ser, até onde sabemos, que tenha chegado bem perto de se compreender a si mesmo; ficamos imaginando, tão-somente, porque um homem precisa adoecer para ter acesso a uma verdade desta espécie (FREUD, 1917/1974, p. 278-279).

Assim, ficaria aqui uma pergunta fundamental: Seria um dos objetivos do suicídio expressar uma verdade essencial, esta "condição humana de falta"? A respeito dessa falta, que Gurfinkel chama de falta constitutiva, o autor irá dizer que ela se refere à perda de um objeto originário. Ele escreverá a esse respeito:

A falta constitutiva, se por um lado é motivo de uma impossibilidade de satisfação plena, por outro é o motor da própria vida psíquica. Aqui surge o desejo, pois diante desta não satisfação é que se origina um impulso de reinvestimento das marcas mnêmicas das experiências de satisfação (GURFINKEL, 1996, p. 163).

A partir dessa passagem, pode-se ver a importância de se falar da falta para o psiquismo humano, pois é assim que o sujeito se faz desejante e vivo do ponto de vista psíquico. A falta põe em questão a onipotência e o princípio do prazer. Mas se essa falta ou perda não pode ser aceita, pode-se prever o surgimento de um sujeito portador de uma necessidade de elaborar seu luto. Gurfinkel (1996) fala da 
perda de um estado primitivo que deixa marcas profundas no sujeito associandoas ao chamado trauma do nascimento, defendido por Julio Aray (apud GURFINKEL, 1996) ${ }^{2}$. Apesar de guardar alguns senões quanto aos autores que defendem tal concepção, Gurfinkel acredita que podem ser feitas leituras mais criativas deste material. Deste modo, considera que o que mais interessa não seria a tese da existência de um psiquismo fetal, mas a relação do sujeito com seu objeto primário (a mãe) e como esta relação irá se desenvolver. Segundo Gurfinkel, no toxicômano é observado com freqüência um vínculo muito frustrante entre mãe e filho, fazendo com que este sujeito busque um objeto substituto do tipo de um "objeto fetiche". Sobre isso ele escreverá:

O objeto substituto (do toxicômano) é, por um lado, um objeto do tipo fetiche - um objeto coisificado, não humano, quase morto - e por outro o corolário de um mecanismo de negação maníaca da perda não elaborada; sob o signo da onipotência destrutiva, há uma desvalorização e uma degradação do objeto, ou seja, o triunfo sobre o objeto e sobre a dor sofrida pela perda (GURFINKEL, 1996, p. 158).

Este objeto do qual fala o autor é a droga e ele também destacará a característica regressiva do adicto dizendo ser a intoxicação "uma tentativa de recuperar o calor materno perdido" (GURFINKEL, 1996, p. 158). Isto evidencia a dificuldade de um luto verdadeiramente simbólico na toxicomania, a possibilidade do toxicômano de fazer um "luto" apenas entre aspas, precário, já que se faz através de um ato que busca um objeto-droga substituto da mãe, ambos os objetos possuidores da função de completar, eliminando ou negando maniacamente as faltas de um sujeito essencialmente melancólico. Havendo uma espécie de luto parcial, como pensar a existência de pulsões de morte (relacionadas à impossibilidade do luto) associadas às pulsões de vida (relacionadas à possibilidade do luto), simultaneamente presentes nas toxicomanias?

\section{As PULSÕES DE MORTE E DE VIDA NESTES TOXICÔMANOS MELANCÓLICOS}

Enquanto melancólico, o toxicômano é um sujeito recolhido em si mesmo, caracterizando-se assim pelo excesso do investimento narcísico. Seu destino não poderá ser outro que aquele de Narciso do mito: a morte, o encontro com as pulsões de morte. Mas, havendo uma substituição da mãe pela droga, algum luto, apesar de tudo, deverá ocorrer, permitindo que se suponha a existência de algum simbolismo, de alguma elaboração, de alguma sublimação e, assim, da convocação das pulsões de vida psíquica. Gurfinkel (1996) parece compartilhar esta idéia quando se interroga até que ponto o toxicômano investe apenas na pulsão de morte, restringindo, assim, seus motivos profundos na simples descarga do impulso de autodestruição. Oliveira; Geraldes \& Silva (1994) também parecem confirmar a mesma hipótese quando procuram defender a idéia de que a pulsão de morte não 
age sozinha, desvinculada da pulsão de vida. Para tanto, as autoras retomam a evolução deste conceito na obra freudiana. Dizem, então, que a pulsão de morte caminha junto com Eros (pulsão de vida), que a junção destes opostos é constitutiva do ser humano. Assim elas escrevem:

Pode-se, ainda, afirmar que a estruturação do psiquismo se dá em função dos pares de opostos, através de um processo que ocorre pela ação das pulsões de vida e de morte, mas, principalmente, pela Pulsão de Morte como responsável pela disjunção e portadora da possibilidade de, ao romper ligações permanentes da pulsão de vida, sair de um estado indiferenciado do narcisismo original, anterior à constituição do eu como sujeito (OLIVEIRA; GERALDES; SILVA, 1994, p. 29).

Portanto a pulsão de morte parece ter aqui um caráter de corte, no sentido de proporcionar ao sujeito o abandono da posição narcísica primordial. Estas autoras, citando Freud, ainda afirmam que a pulsão de morte não guarda nenhum representante psíquico no inconsciente, mas que se pode "suspeitá-lo, "num segundo plano, por trás de Eros, fugindo à detecção, a menos que sua presença seja traída pelo fato de estar ligado a Eros"” (OLIVEIRA; GERALDES; SILVA, 1994, p. 29).

Gurfinkel (1993, p. 171) mencionará esta possibilidade da ação das pulsões de morte integradas com as pulsões de vida nas toxicomanias quando escreve: "Quando o uso de droga vem acompanhado de uma tentativa de construção de um espaço psíquico de ilusão, de criatividade ou de jogo, poderíamos supor o trabalho de Eros". Poder-se-ia perguntar: A tentativa de suicídio como expressão da elaboração profunda do $\mathrm{Eu}$, conforme foi hipotetizado acima no item $2^{\circ}$, não seria justamente o resultado desta ação integrada e simultânea de Thanatos e de Eros na construção da verdade subjetiva?

Pelo que já foi discutido, a conduta autodestrutiva na drogadicção não pode ser entendida como constituindo o resultado da simples e pura descarga da pulsão de morte. Ela "simboliza" alguma coisa, alguma perda fundamental, pois a droga não é efetivamente a mãe, embora também a repita. Chega-se a conclusão de que esses atos de intoxicação simultaneamente falam e silenciam. Existe assim alguma "simbolização", não por palavras, mas por atos. Pela própria natureza de ato da toxicomania, ela não simboliza por palavras, pois suas pulsões pré-genitais não foram reprimidas, de modo a dar espaço à primazia genital, base da sublimação. Gurfinkel (1996, p. 216-217) escreverá sobre isso:

Ora, o que observamos é que a compulsão repetitiva traz em si tanto a negatividade quanto a positividade. Quando Freud propõe o modelo da compulsão à repetição, sugere que nesta atividade haveria um trabalho psíquico de ligação, que não 
deixa de ter um caráter positivo; a sua característica principal não é uma suposta negatividade (tendência de retorno ao inorgânico), mas sim uma forma especial de trabalho psíquico diferente daquele usualmente conhecido: a sua meta é administrar um excesso insuportável, independente da maneira de fazê-lo, ou seja, desconsiderando o signo do prazer. (...) Se há alguma negatividade intrínseca à compulsão à repetição, trata-se do repúdio sistemático a abrir-se a qualquer experiência nova, já que a única tarefa possível é 'digerir' uma experiência traumática não elaborada: aí a repetição ocupa todo o campo da experiência. (...)

Se a compulsão à repetição abriu o caminho para a pulsão de morte, tornou-se insuficiente para dar conta de sua negatividade mais radical. Os referenciais utilizados por Freud - o sonho traumático, o jogo infantil - não seriam hoje considerados como prototípicos da pulsão de morte, já que neles não se evidencia uma função radical de desligamento; pois a pulsão de morte deixou de ser uma forma defensiva extrema através da ligação para ser a 'solução final' do desligamento diante da perturbação intolerável.

Além disso, Gurfinkel (1996) falará também da positividade do narcisismo, observado em excesso nas toxicomanias. O lado negativo do narcisismo aparecerá na maior parte de tudo o que se fala a respeito das toxicomanias: a fuga da realidade, a procura por uma relação fusional-narcísica, a recusa da falta constitutiva, etc. No entanto, parece que é deixado de lado a função estruturante do narcisismo. Gurfinkel (1996) não nega o que denomina de negativo do narcisismo, mas diz que este pode muitas vezes ser um valor imposto pelo analista devido à frustração de um ideal de cura. Assim, coloca a importância de se considerar a duplicidade do narcisismo, de constituição e desconstituição, simultaneamente: “(...) Se é o narcisismo que constitui o eu como o lugar da alienação do sujeito em relação ao seu desejo, é a dialética das identificações entre eu e objeto - sempre permeada pela posição narcisista - o movimento vital do crescimento psíquico" (GURFINKEL, 1996, p. 179).

De qualquer forma, é difícil compreender como a repetição de uma atuação - a da autodestrutividade na drogadicção - pode também ser considerada uma tentativa de elaboração, dado a sua pobreza de simbolização, ao seu silêncio e a presença da pulsão de morte. Para entender melhor e aprofundar tal questão será discutido no item seguinte modelo do fort-da de Freud, já que essa noção se baseia fundamentalmente na repetição de um ato que simultaneamente representa impossibilidade e possibilidade de elaboração de luto. 


\section{O MODELO DO FORT-DA NA COMPULSÃO À REPETIÇÃO DAS TOXICOMANIAS E SUA DUPLA FUNÇÃO DE POSSIBILITAR E IMPOSSIBILITAR A ELABORAÇÃO DO LUTO}

Freud se perguntava qual seria o prazer envolvido na brincadeira do fort$d a$, se a partida da mãe não pode ter sido vivida como algo agradável, e como esta situação se harmonizaria com o princípio do prazer. A resposta a que chegou foi que a partida da mãe (o-o-ó) teria que ser representada para que o seu retorno (da) pudesse ser experienciado através da brincadeira. $\mathrm{O}$ ganho deste movimento poderia, segundo Freud, residir na tomada de uma posição ativa diante de algo que antes fora sofrido de forma passiva. O autor falou também que o interesse envolvido nesta brincadeira estaria relacionado a algo mais além do princípio do prazer, embora implicando na produção num outro tipo de prazer. Assim ele escreverá:

(...) Assim, ficamos em dúvida quanto a saber se o impulso para elaborar na mente alguma experiência de dominação, de modo a tornar-se senhor dela, pode encontrar expressão como um evento primário e independentemente do princípio do prazer. Isso porque, no caso que acabamos de estudar, a criança, afinal de contas, só foi capaz de repetir sua experiência desagradável na brincadeira porque a repetição trazia consigo uma produção de prazer de outro tipo, uma produção mais direta (FREUD, 1920a/1976a, p. 28).

Ou seja, Freud ao mencionar um "impulso para elaborar na mente alguma experiência", chega perto do que pode ser algo prazeroso enquanto elaboração através da brincadeira. E esse impulso à elaboração faz uso da repetição. O que se repete é algo que fora vivido como desagradável porque carecia de elaboração. Freud (1920a/1976a, p. 28-29) esclarecerá esta idéia:

(...) porém, é óbvio que todas as suas brincadeiras são influenciadas por um desejo que as domina o tempo todo: o desejo de crescer e poder fazer o que as pessoas crescidas fazem.

(...) Isso constitui prova convincente de que, mesmo sob a dominância do princípio de prazer, há maneiras e meios suficientes para tornar o que em si mesmo é desagradável num tema a ser rememorado e elaborado na mente.

Deste modo, Freud introduz aqui a idéia de crescimento psíquico que a repetição na brincadeira envolve. E parece que esta idéia de crescimento vem associada à idéia de que a brincadeira consiste num saber lidar com uma realidade que não satisfaz as exigências infantis.

A respeito disso, pode-se evocar também as contribuições de Winnicott sobre esta idéia da brincadeira como forma facilitadora do crescimento interno. Para 
este autor, o brincar da criança é um exercício de transição entre o interior e o exterior, a invenção de um espaço potencial entre o eu e o não-eu. Este espaço mais tarde sustentaria o campo cultural do adulto. Sobre isso, Rassial (1999, p. 9192) também terá algo a dizer:

Assim, o brinquedo é o objeto que produz e concretiza este espaço, primeiramente na relação com a mãe, depois com o meio. O destino deste objeto é variável: pode ser fetichizado, tornar-se fobogênico, ou então abrir-se, através de sua representação, impossível em definitivo, para o campo simbólico.

O objeto do qual fala Rassial é o objeto transicional. É Winnicott (1975) quem o propõe, caracterizando-o como representante do seio materno, do objeto da primeira relação, como um objeto que precede o simbolismo, o teste da realidade. Winnicott $(1975$, p. 23$)$ ainda diz que "na relação com o objeto transicional, o bebê passa do controle onipotente (mágico) para o controle pela manipulação (envolvendo o erotismo muscular e o prazer de coordenação)".

Mas de que modo a problemática da brincadeira infantil toca a questão das toxicomanias? E como a repetição e, então, a perspectiva de elaboração, manifesta no jogo infantil do fort-da, se relaciona com a drogadicção? GURFINKEL (1996, p. 205) responde a estas questões afirmando que a compulsão à repetição está presente nas toxicomanias, da seguinte forma:

A toxicomania caracteriza-se fundamentalmente por uma conduta repetitiva: uma compulsão irrefreável leva o adicto a recorrer sempre de novo à droga. Este, sem dúvida, é o elemento inicial para pensarmos a relação da toxicomania com a pulsão de morte.

Gurfinkel (1996, p.198) ainda diz que a finalidade desta compulsão à repetição é "ligar a excitação com o objetivo de dominá-la, e (que) o seu caráter compulsivo é compreendido pela necessidade de esgotar a excitação perturbadora". Conforme este autor, o jogo do fort-da também teria a finalidade de ligação das excitações que ultrapassam a capacidade de elaboração de um frágil psiquismo. Citando Ocampo e Rosenfeld, Gurfinkel (1996, p.210) acrescentará "que uma experiência originária de insatisfação (será) um fator determinante (na) etiologia (da toxicomania): (...) um vínculo especialmente frustrante com a mãe em períodos muito precoces do desenvolvimento". O trauma se daria pela afluência de excitações vividas como insuportáveis para um aparelho psíquico incapaz de elaborá-las. Finalmente, Gurfinkel (1996, p. 209-210) escreverá:

$\mathrm{Na}$ experiência do toxicômano, a droga se torna, com o estabelecimento da adicção, um 'objeto específico' - objeto exclusivo de um prazer necessário - cuja ausência coloca o sujeito em um estado de carência insuportável. Esta experiência é, pois, a reprodução atualizada da 'experiência originária de insatisfação', e o encontro com a droga reativa 
- por um processo regressivo - a situação traumática com o objeto primário/mãe: um objeto ardentemente esperado por um psiquismo prematuramente colocado em um universo hostil e incompreensível, um objeto que é ao mesmo tempo o único a garantir a sobrevivência e o veículo, por sua ausência, da experiência do insuportável.

Vê-se, então, que o "movimento da drogadicção" - com droga / sem droga -, abre perspectivas de elaboração. Através deste movimento, repete-se outro movimento bem mais fundamental: fusão com a mãe / separação da mãe. E, como já foi visto acima no item 3o, esta repetição não é somente uma manifestação da pulsão de morte, mas também da pulsão de vida, pois permite alguma "simbolização". Poder-se-ia, então, dizer que a tentativa de suicídio pela overdose na drogadicção constitui-se enquanto ensaio de elaboração, realizando, assim, algum luto pela perda de um vínculo de completude com o corpo materno.

Rassial (1999, p. 92) propõe a drogadicção como uma espécie de "brincadeira" que tem como brinquedo a própria droga, afirmando que, em pesquisas psicanalíticas, "já se chegou a avançar que o objeto tóxico derivava deste objeto transicional, talvez (...) porque o comportamento toxicomaníaco (seja) diretamente associável às brincadeiras da criança". O mesmo autor ainda dirá que o efeito buscado pelas drogas é o correlato da experiência do brincar, pois se constitui como uma "invenção de um campo espaço-temporal diferente da realidade socialmente organizada e intermediário entre o interior e o exterior". Ou seja, tanto a experiência com a droga, quanto aquela com o brincar, parecem trazer em si, pelo exercício de uma fantasia, a função de fazer um intermédio entre as necessidades internas do sujeito e o gradual estabelecimento do princípio de realidade, num exercício que, como já foi visto, permite o crescimento psíquico. No entanto, Rassial (1999, p. 92) proporá também uma diferenciação entre o brincar infantil e o uso de drogas:

(...) no discurso dos toxicômanos, os inícios são geralmente evocados como do registro do brincar. $\mathrm{Na}$ realidade, o uso das drogas situa-se entre a atividade lúdica da criança e as atividades de sublimação socializadas: a arte, a religião, os processos intelectuais .

Assim, segundo Rassial, o uso de drogas ganha o status de algo da ordem de uma "quase simbolização" pela posição intermediária que irá ocupar entre a atividade lúdica e as atividades de sublimação, aproximando-se mais da realidade.

Gurfinkel (1996, p. 180) também concordará com esta idéia, pois escreverá a esse respeito:

A experiência com a droga encontra-se no espaço intermediário de ilusão - uma neo-realidade - que pode ser um afastamento da realidade mas também, sob outro prisma, uma estratégia de aproximação com ela por um caminho intermediário, o único possível por ora. 
Gurfinkel aponta, então, que a drogadicção parece uma possibilidade, talvez a única, ao alcance de sujeitos que não puderam alcançar uma forma socializada de sublimação, devido possivelmente a alguma insuficiência na elaboração de lutos. Ela se apresenta aqui como permitindo algum grau de elaboração do luto, embora também implique na impossibilidade de uma elaboração suficiente.

Para ilustrar a clínica da auto-destruição como revelando esta dupla possibilidade e impossibilidade de elaboração de luto, primeiramente, no item 5o, será feito um retorno a Freud para apresentar dois casos desse autor que, mesmo não sendo drogadictos, fazem referência ao suicídio. Em seguida, no item 6o, será analisada a natureza do "luto" realizado por estes casos nesta referência ao suicídio. Finalmente, no item 7o, os achados dos itens 5 o e 60 serão utilizados como parâmetro para se pensar a questão da drogadicção como tentativa de suicídio e, mais precisamente, para analisar a perspectiva elaborativa de se fazer algum luto através desta tentativa de suicídio pela ingestão de drogas.

\section{O SUICÍDIO REFERIDO EM DOIS CASOS DE FREUD}

Pretende-se a seguir analisar dois casos clínicos de Freud relatados em: 1o"A psicogênese de um caso de homossexualismo numa mulher" (FREUD, 1920b/ 1976b); e 2o- "Fragmento da análise de um caso de histeria", o Caso Dora (FREUD, 1905/1972). Trata-se das curas de duas adolescentes, ambas da mesma idade, 18 anos, que em determinado momento de suas vidas colocam em questão sua identidade homossexual. No primeiro caso encontra-se uma tentativa de suicídio, enquanto que em Dora se verá apenas uma ameaça de tentativa de suicídio. A comparação desses casos envolvendo a temática do suicídio será fundamental para a compreensão da diferença entre os mesmos, o que servirá de parâmetro para que se pense, no item 7o deste trabalho, a perspectiva de simbolização, de se fazer algum luto, através da tentativa de suicídio pela drogadicção.

Sobre o primeiro caso, Freud (1920b/1976b) começa dizendo que se trata de uma jovem homossexual, cortesã, enamorada de uma "dama da sociedade". A consciência desta diferença social nesta moça não parecia abalar seus sentimentos pela senhora. A jovem não fazia questão alguma de esconder essa sua "amizade", sendo negligente com sua reputação, fato que acabou lhe custando uma tentativa de suicídio. Após esta tentativa, Freud foi chamado para analisá-la pelo pai da jovem. Este, mesmo descrente da técnica psicanalítica, sabendo das tendências homossexuais da filha, estava tentando tudo para auxiliar a filha. Para ele, esta não era mais do que uma "viciosa, ou degenerada ou mentalmente perturbada" (FREUD, 1920b/1976b, p.187). Com a mãe, no entanto, a relação da jovem era um tanto mais tranqüila, mas, mesmo assim, a moça guardava certa reserva. Freud, desde o início, mostrava-se descrente quanto ao tratamento. A adolescente não demonstrava demanda em livrar-se de seu homossexualismo e havia concordado com o tratamento única e exclusivamente pelos pais. Freud relatou a história sexual do 
caso, procurando refletir a gênese do seu homossexualismo. Conforme afirma, sua saída do complexo edípico não teria sido bem sucedida. A causa disso seria o nascimento do seu irmão mais novo. Sua homossexualidade, de acordo com Freud, era uma forma de vingar-se do pai e de buscar uma substituta da mãe. A respeito da tentativa de suicídio dessa jovem, Freud (1920b/1976b, p. 201) escreverá:

A tentativa de suicídio, como se podia esperar, foi determinada por dois outros motivos, além do que ela forneceu: a realização de uma punição (autopunição) e a realização de um desejo. Esse último significava a consecução do próprio desejo que, quando frustrado, a impelira ao homossexualismo: o desejo de ter um filho do pai.

Sua tentativa de autopunição era um impulso assassino contra os pais. Freud (1920b/1976b, p. 201-202) explicou a esse respeito:

A ação da jovem nos mostra que desenvolvera no inconsciente intensos desejos de morte contra um ou outro de seus genitores, talvez contra o pai, como vingança por impedir seu amor, porém mais provavelmente contra a mãe, quando grávida do irmão pequeno.

Freud não chegou a ir muito longe nessa análise, pois a situação transferencial assim não permitia. Sobre a resistência do caso, Freud (1920b/1976b, p. 203) esclareceu: "Parecia, ademais, como se nada semelhante a uma transferência para o médico se houvesse efetuado". No entanto, como isso lhe pareceu por outro lado absurdo, já que é impossível se conceber um estado clínico sem qualquer transferência, Freud preferiu interpretar que o que a moça estava lhe transferindo era o azedume contra os homens. Este aparecia, sem que ela precisasse se utilizar manifestações emocionais violentas, através de sua indiferença aos esforços de Freud e de seu apego a sua doença.

Sobre o Caso Dora, Freud inicia dizendo se tratar de uma jovem de 18 anos, inteligente e muito apegada à figura do pai. A mãe da moça, segundo relato dela própria, era descrita como sendo uma obsessiva por limpeza. Dora apresentava sintomas neuróticos desde os 8 anos de idade. Havia sido tratada por inúmeros médicos, nos quais já não depositava credibilidade alguma. Freud (1905/1972, p. 21) assim descreverá a doença de sua paciente:

A melancolia e uma alteração de caráter se tinham tornado agora os principais traços de sua doença. Ela, de modo evidente, não estava satisfeita consigo mesma nem com a família; sua atitude em relação ao pai era inamistosa, e mantinha péssimas relações com a mãe que estava determinada a fazê-la participar dos trabalhos da casa. (...) Um dia seus pais ficaram bastante alarmados ao encontrar sobre a escrivaninha da moça, ou dentro dela, uma carta em que ela se despedia deles porque, dizia, não podia suportar mais a vida. 
Freud disse que chegou a mencionar esta carta a Dora, pois ela lhe havia dado a entender que sabia que seus pais a tinham em seu poder. Assim, pode deduzir que ela própria havia providenciado que isto acontecesse. O pai da moça teria ficado abalado com esta ameaça de suicídio e tomado a resolução de procurar Freud após a primeira perda de consciência da moça. O diagnóstico feito por Freud foi o de histeria, baseado nos sintomas somáticos e mentais de "dispnéia, tussis nervosa, afonia, e possivelmente enxaquecas, juntamente com depressão, insociabilidade histérica e um taedium vitae que provavelmente não era de todo autêntico" (FREUD, 1905/1972, p. 21-22).

Sobre os prováveis fatores desencadeantes da doença, o próprio pai da moça mencionou a aproximação dos K. O adoecimento e sua ameaça de suicídio apareceram após um incidente ocorrido numa temporada de Dora na casa dos K., aonde a adolescente teria dado uma bofetada no Sr. K. Assim relatou Freud (1905/1972, p. 23): "Só alguns dias mais tarde ela (Dora) esclarecera seu estranho comportamento. Contara então à mãe - com o propósito de que o que dissesse fosse transmitido ao pai - que Herr K. tivera a audácia de fazer-lhe uma proposta amorosa, enquanto andavam depois de um passeio ao lago". O Sr. K. fora chamado para dar explicações, mas negara tudo. Além disso, Dora fora traída pela Sra. K., a quem já havia demonstrado sinais de afeto. A respeito disso, o pai de Dora teria dito, segundo Freud (1905/1972, p. 24): “Não tenho dúvida', (...), 'de que esse incidente é responsável pela depressão e irritabilidade de Dora e pelas suas idéias suicidas"”.

No decorrer da análise de Dora, Freud ficou a par de sua raiva pelo pai devido ao fato dele não ter satisfeito sua exigência: romper com os K. Freud hipotetizou, então, que o pai de Dora e a Sra. K. mantinham um relacionamento amoroso. Sabia-se também que o próprio pai de Dora havia feito uma ameaça de suicídio como forma de apelo a Sra. K, antes dele próprio adoecer. Freud explicou que era exatamente este o ponto de ligação com a simulação de suicídio da própria Dora: ela assim talvez expressasse o anseio por um amor similar. Logo, a explicação última que Freud dará sobre o motivo da ameaça de suicídio de Dora e de seus adoecimentos anteriores seguirá a mesma idéia: expressar um pedido de amor. Freud interpretará, por exemplo, as crises de afonia de Dora como associadas à ausência do Sr. K.; e sua ameaça de suicídio como um modo de afastar o pai da Sra. K.

No entanto, Freud (1905/1972, p. 57-8) admitiu que algo pudesse ter lhe escapado e, assim, escreveu:

O elemento a que devo aludir agora só pode servir para obscurecer e apagar as linhas gerais do delicado conflito poético que pudemos atribuir a Dora. Este elemento constituiria certamente um sacrifício para a censura de um escritor, pois ele, afinal de contas, simplifica e resume quando aparece na qualidade de psicólogo. (...) Pois atrás da seqüência prevalente de pensamentos de Dora ligados às relações entre seu pai e Frau K. havia oculto um sentimento de ciúme que 
tinha aquela senhora como objeto - um sentimento, isto é; que só se podia fundar numa afeição de Dora por alguém de seu próprio sexo. (...)

Neste ponto não abordarei mais este importante assunto, (...) porque a análise de Dora terminou antes que pudesse esclarecer este lado de sua vida mental.

Deste modo, a falha de Freud na análise de Dora foi não ter trabalhado sua homossexualidade.

Eis aqui a ilustração de dois casos envolvendo homossexualidade, suicídio e dificuldade de acesso ao simbólico no contexto analítico. No item seguinte pretende-se analisar a relação entre tais expressões do suicídio e a perspectiva de acesso ao simbólico, de elaboração de luto.

\section{Do ACTING-OUT de DORA À PASSAGEM AO ATO DA JOVEM HOMOSSEXUAL E SUAS POSSIBILIDADES E IMPOSSIBILIDADES DE ELABORAÇÃO DE LUTO ATRAVÉS DA REFERÊNCIA AO SUICÍDIO}

Existirá alguma diferença fundamental entre estas duas referências ao ato de suicídio nestes casos de Freud envolvendo "homossexualidade feminina na adolescência" acima apresentados? Alguns autores já se ocuparam da distinção entre estes dois casos de Freud envolvendo a temática do suicídio. Este é o caso, por exemplo, de Alberti (1996), apoiada em Lacan, que será a seguir retomada para alimentar a discussão sobre esta diferenciação. O que se pretende com este paralelo é, em última instância, encontrar subsídios teóricos que sirvam de parâmetro para se pensar a questão central deste trabalho: Numa tentativa de suicídio via droga poderia existir alguma perspectiva de simbolização, de elaboração de luto?

Antes de entrar na discussão da questão principal deste item, caberia retomar a distinção que Lacan faz entre "passagem ao ato" e "acting-out", o que será de fundamental importância para a posterior diferenciação dos dois casos de Freud apresentados acima. Melman (1999, p. 38), tratando da clínica do adolescente, retomará esta distinção lacaniana e dirá que o "acting-out" é um pedido de ajuda na transferência, enquanto as "passagens ao ato" não levam em consideração a existência de um outro a quem se possa pedir algo, acrescentando ainda:

(...) ou se trata de um pedido (no caso do acting-out), podemos dizer de um apelo ao Pai, ao Pai ideal, (...) a um Pai não castrado que teria a possibilidade de dar a seus filhos um acesso a um mundo que fosse menos deficitário do que aquele em que está (...), ou se tratam de manifestações que testemunham, direi em duas palavras, de um estado sem transferência (passagem ao ato). 
Deste modo, o autor coloca o "acting-out" do lado da transferência ao outro, e a "passagem ao ato" como um apelo ao Outro, um ideal sem outro, sem objeto, aonde "o que está ausente é a sanção simbólica" (MELMAN, 1999, p. 40). Este autor ainda acrescentará:

Por um lado, haveria na adolescência aqueles cujas manifestações constituem "actings out", pedidos de ajuda a esse Pai ideal, ou seja, a expressão de uma transferência em curso. Haverá outros, ao contrário, que não esperam nada de ninguém e para os quais o mundo é percebido como um caos, no qual teriam que apenas tentar se safar (MELMAN, 1999, p. 39).

Alberti (1996) também retomará a mesma distinção lacaniana, aproximando o acting-out do que chama de "reação favorável" e a atuação da "reação negativa". Na primeira pode-se encontrar o sujeito, mas na última não. Assim, Alberti (1996, p. 78) escreverá:

A "reação favorável" encontra-se diante do ato falho, introduzido na Psicopatologia da vida cotidiana. Se o sonho leva em conta a Rücksicht auf Darstellbarkeit em seu conteúdo manifesto - o que quer dizer, em termos lacanianos, a implicação do sujeito no sonho -, o ato falho é, talvez mais do que o sonho, a via real de acesso ao inconsciente, posto que o sujeito que se reconhece como tal é deixado de lado no ato falho - pura irrupção do inconsciente.

A "reação negativa" tem lugar diante da noção de ação Handlung nas "Formulações dos dois princípios do funcionamento psíquico" -, que consiste numa soma de ações experimentais, de pensamentos experimentais. Para Lacan o ato não é um pensamento, ele está ou ali onde "eu não penso" ou bem lá onde "eu não sou".

Alberti (1996) ainda retomará de Lacan a comparação que ele fez entre a bofetada de Dora e a tentativa de suicídio da jovem homossexual, dizendo que o que se encontra ali em ambos os casos é uma passagem ao ato. Assim, ela escreverá:

Lacan diz que essa saída da cena é própria da estrutura da passagem ao ato em Dora, implicando a seguinte formulação: "se sua mulher não é nada para o senhor, então o que é uma mulher para o senhor? o que eu sou para o senhor? nada?". (...)

Ao nomear a tentativa de suicídio da jovem homossexual um Niederkommen (cair que equivoca com parir, em alemão), Freud tenta dar conta dela apontando para o equívoco desse significante. Mas esse Niederkommen não dá conta da radicalidade do ato, porque o radical em jogo, na tentativa de suicídio dessa jovem, é da ordem do real e não do simbólico (ALBERTI, 1996, p. 80-1). 
O que Alberti considera, finalmente, é que a tentativa de suicídio da jovem homossexual, assim como a saída de cena de Dora no lago, constituem-se como sendo da ordem de algo que subtrai o sujeito do registro do simbólico para colocálo no lugar do real.

Retomando as duas referências ao suicídio, pode-se, então, concluir que, na tentativa de suicídio da jovem homossexual, o sujeito escapa para o real, prejudicando a possibilidade de simbolização, passando efetivamente ao ato. Já em Dora, quando ela escreve sua carta de despedida, o simbólico antecede a perspectiva da passagem ao ato que de fato não ocorre. Em Dora existe apenas uma ameaça de tentativa de suicídio.

Pode-se agora retomar as toxicomanias e interrogar: A partir da análise destas contribuições de Freud sobre estas duas referências ao suicídio, como pensar a tentativa de suicídio pela ingestão droga?

\section{A tentativa de SUicídio PEla dRogadicÇão:} ACTING-OUT ELABORATIVO DO LUTO PRIMORDIAL OU PASSAGEM AO ATO SEM QUALQUER ELABORAÇÃO DESTE LUTO?

Pelo que foi exposto acima, pode-se concluir que existem pelos menos duas formas de se expressar a tentativa de suicídio, uma sob a forma de ameaça, aonde surge alguma possibilidade de simbolização, e outra, sob a forma de ato, aonde a simbolização encontra-se dificultada. Também se pode ver que a simbolização aparecerá ali aonde se encontra também um sujeito ou, como diria Lacan, lá aonde se faz presente o desejo e a falta. Mas, aonde situar as toxicomanias? Pode-se encontrar um sujeito na lenta autodestruição da drogadicção? Há desejo aí? Se sim, de que forma? Para discutir tais questões não seria interessante retomar o critério apontado por Alberti (1996) e interrogar mais precisamente: Pode-se encontrar na drogadicção o que a autora chama de "reação favorável"?

Pelo exposto acima, acredita-se ser possível concluir que se o parâmetro for o ideal da cura analítica, a drogadicção não poderia ser considerada uma "reação favorável", pois situa-se do lado do real, da passagem ao ato. Contudo, se emprestado o modelo de reflexão de Rassial (1999, p. 92) acima discutido no item 4o, não se poderia dizer que "o uso das drogas situa-se entre a atividade lúdica da criança e as atividades de sublimação socializadas: a arte, a religião, os processos intelectuais", constituindo assim uma espécie de "quase simbolização" situada nesta posição intermediária entre a brincadeira infantil e a perspectiva ideal de elaboração adulta no campo das sublimações? Se sim, não se poderia dizer que algum grau de "simbolização" da falta haveria na drogadicção, constituindo-se ela como um acting-out? 


\section{Conclusão}

Este trabalho essencialmente teórico interrogou se a drogadicção poderia ser compreendida como gozo pela descarga da pulsão de morte sobre si próprio, ou se haveria simultaneamente a convocação da pulsão de vida nestes atos de se auto-destruir, nestas tentativas de suicídio pela ingestão de drogas. Chegou-se à conclusão que existiria na toxicomania a ação simultânea das pulsões de morte e de vida. A drogadicção traria, então, ao mesmo tempo, um silêncio e alguma perspectiva de "simbolização". Ela estaria assim situada num lugar intermediário entre a brincadeira infantil e o ideal de cura analítica pelo acesso ao simbólico através do luto pela perda original. A auto-destruição, a tentativa de suicídio pela ingestão de drogas, foram entendidas como, ao mesmo tempo, melancolia e negação maníaca. Significariam um ataque ao próprio corpo para, assim, atacar o corpo da mãe e, desta forma, romper este vínculo, o que traria certo grau de elaboração da perda da completude ilusória pela fusão com este objeto primordial.

De qualquer forma, antes de concluir afirmando uma suposta verdade de caráter genérico e teórico, se acredita mais produtivo ser humilde na generalidade e se restringir às considerações mais relativas a cada caso. Como este trabalho foi essencialmente teórico, pretende-se em estudos posteriores realizar um estudo de caso sobre a temática aqui em debate para, então, aprofundar as questões acima em destaque, com uma perspectiva mais restrita ao particular do caso estudado. Afinal de contas, cada caso é um caso.

\section{Notas}

${ }^{1}$ Este trabalho foi retirado da Monografia de Conclusão de Curso de Graduação em Psicologia pela UFPR - Universidade Federal do Paraná da primeira autora deste artigo, não-publicada, intitulada: "Drogadição: suicídio ou (e) elaboração? Algumas considerações psicanalíticas", desenvolvida no CET - Centro de Estudos das Toxicomanias Dr. Claude Olievenstein da UFPR, sob a orientação do segundo autor deste trabalho, defendida e aprovada em dezembro de 2001. Para os detalhes desta monografia, vide Mansilla (2001).

2 Julio Aray, autor da obra "Adicción y Regressión fetal", defendeu a idéia de que o adicto tenta reproduzir um estado semelhante ao da vida intra-uterina, ou seja, defende a idéia de um "psiquismo fetal". Gurfinkel critica aqui o fato de autores como Aray realizarem uma interpretação literal do narcisismo primitivo de Freud e comenta: "Infelizmente, o trabalho de Aray tem um caráter geral e sintético, estando mais voltado para defender a tese da regressão fetal do que para trabalhar as nuances da clínica da toxicomania". (GURFINKEL, 1996, p.159-60). 


\section{REFERÊNCIAS}

ALBERTI, S. Esse sujeito adolescente. Rio de Janeiro: Relume-Dumará, 1996.

FREUD, S. Fragmento da análise de um caso de histeria. In: . Edição standard brasileira das obras psicológicas completas de Sigmund Freud. Rio de Janeiro: Imago. 1905/1972. v. VII, p. 1-117.

. Luto e melancolia. In: . Edição standard brasileira das obras

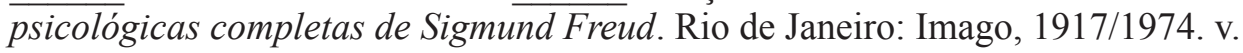
XIV, p. 269-291.

. Além do princípio de prazer. In: . Edição standard brasileira das $\overline{\text { obras p }}$ sicológicas completas de Sigmund Freud. Rio de Janeiro: Imago, 1920a/ 1976a. v. XVIII, p. 11-85.

.A psicogênese de um caso de homossexualismo numa mulher. In: $\overline{\text { Edição standard brasileira das obras psicológicas completas de Sigmun } \overline{\mathrm{F}} \text { Freud. }}$. Rio de Janeiro: Imago, 1920b/1976b. v. XVIII, p. 181-212.

GURFINKEL, D. Introdução a uma abordagem psicanalítica da questão das drogas na adolescência. In: RAPPAPORT, C. R. (Coord.). Adolescência: abordagem psicanalítica. São Paulo: EPU, 1993. p. 131-174.

. A pulsão e seu objeto-droga: estudo psicanalítico sobre a toxicomania. Petrópolis, Rio de Janeiro: Vozes, 1996.

KALINA, E. et al. Drogadição hoje: indivíduo, família e sociedade. Porto Alegre, RS: Artes Médicas, 1999.

KOVÁCS, M. J. (Coord.). Morte e desenvolvimento humano. São Paulo: Casa do Psicólogo, 1992.

MANSILLA, N. K. R. Drogadicção: suicídio ou (e) elaboração? Algumas considerações psicanalíticas. 2001. Monografia (Graduação em Psicologia)-CET - Centro de Estudos das Toxicomanias Dr. Claude Olievenstein da UFPR Universidade Federal do Paraná, Curitiba, PR, 2001.

MELMAN, C. Os adolescentes estão sempre confrontados ao minotauro. In: Associação Psicanalítica de Porto Alegre (Ed.). Adolescência: entre o passado e o futuro. Porto Alegre, RS: Artes e Ofícios, 1999. p. 29-43.

OLIVEIRA, M. L. C. B.; GERALDES, M. T. de M.; SILVA, C. M. da. O silêncio da pulsão de morte. Jornal Brasileiro de Psiquiatria, Rio de Janeiro, v.43, n. 1, p. 29-37, jan. 1994.

RASSIAL, J.-J. $O$ adolescente e o psicanalista. Rio de Janeiro: Companhia de Freud, 1999.

WINNICOTT, D. W. O brincar \& a realidade. Rio de Janeiro: Imago, 1975.

Recebido em: março/ 2006.

Aceito em: outubro/ 2006. 